University of Wollongong

Research Online

Faculty of Engineering and Information

Faculty of Engineering and Information

Sciences - Papers: Part B

Sciences

2020

\title{
Three-Dimensional Velocity Distribution in Straight Smooth Channels Modeled by Modified Log-Law
}

Shu-qing Yang

University of Wollongong, shuqing@uow.edu.au

Muhammad Zain Bin Riaz

University of Wollongong, mzbr518@uowmail.edu.au

Muttucumaru Sivakumar

University of Wollongong, siva@uow.edu.au

Keith Enever

University of Wollongong, kenever@uow.edu.au

Nadeeka Miguntanna

University of Wollongong, nsm587@uowmail.edu.au

Follow this and additional works at: https://ro.uow.edu.au/eispapers1

Part of the Engineering Commons, and the Science and Technology Studies Commons

Research Online is the open access institutional repository for the University of Wollongong. For further information contact the UOW Library: research-pubs@uow.edu.au 


\title{
Three-Dimensional Velocity Distribution in Straight Smooth Channels Modeled by Modified Log-Law
}

\author{
Abstract \\ Time-average velocity distribution in steady and uniform channel flows is important for fundamental \\ research and practical application as it is always three-dimensional (3D), regardless of channel geometry. \\ However, its determination has predominantly been carried out by using complex numerical software, \\ even for the simplest geometry such as rectangular channels. The log-law was developed initially for \\ circular pipe flows, where a single shear velocity is used to normalize the velocity $(u+)$ and its distance \\ $(y+)$. Tracy and Lester found that the performance of the log-law can be extended to express velocity \\ profiles in rectangular channels when the global shear velocities (gRS) 0.5 and (ghS) 0.5 are used to \\ normalize the measured velocity $u$ and its distance $y$. This study extends this discovery from the channel \\ central line to the corner regions, and its general form of log-law was found to be valid even in trapezoidal \\ or triangular open channels or closed ducts. This modified log-law can produce good agreement with the \\ measured velocity with an average error of less than $5 \%$. Therefore, this study provides a simple and \\ reliable tool for engineers and researchers to estimate the velocity contours in straight and smooth \\ channel flows.
}

\section{Keywords}

straight, smooth, velocity, modeled, channels, modified, log-law, three-dimensional, distribution

\section{Disciplines}

Engineering | Science and Technology Studies

\section{Publication Details}

Yang, S., Riaz, M., Sivakumar, M., Enever, K. \& Miguntanna, N. Sajeewani. (2020). Three-Dimensional Velocity Distribution in Straight Smooth Channels Modeled by Modified Log-Law. Journal of Fluids Engineering, 142 (1), 011401-1-011401-8. 


\title{
3-D velocity distribution in straight smooth channels modelled by modified log-law
}

\section{Shu-Qing Yang}

School of Civil, Mining and Environmental Engineering, University of Wollongong, Wollongong 2522, NSW, Australia

shuqing@uow.edu.au

Muhammad Zain Bin Riaz ${ }^{1}$

School of Civil, Mining and Environmental Engineering, University of Wollongong, Wollongong 2522, NSW, Australia

mzbr518@uowmail.edu.au

\section{Muttucumaru Sivakumar}

School of Civil, Mining and Environmental Engineering, University of Wollongong, Wollongong 2522, NSW, Australia

siva@uow.edu.au

\section{Keith Enever}

School of Mechanical, Materials, Mechatronic and Biomedical Engineering, University of Wollongong, Wollongong 2522, NSW, Australia

kenever@uow.edu.au

\section{Nadeeka Sajeewani Miguntanna}

School of Civil, Mining and Environmental Engineering, University of Wollongong, Wollongong 2522, NSW, Australia

nsm587@uowmail.edu.au

\begin{abstract}
Time-average velocity distribution in steady and uniform channel flows is important for fundamental research and practical application as it is always three-dimensional, regardless of channel geometry. However, its determination has predominantly been carried out by using complex numerical software, even for the simplest geometry such as rectangular channels. The log-law was developed initially for circular pipe flows, where a single shear velocity is used to normalize the velocity $\left(\mathrm{u}^{+}\right)$and its distance $\left(\mathrm{y}^{+}\right)$. Tracy and Lester found that the performance of the log-law can be extended to express velocity profiles in rectangular channels when the global shear velocity $(\mathrm{gRS})^{0.5}$ and $(\mathrm{ghS})^{0.5}$ are used to normalize the measured velocity $\mathrm{u}$ and its distance y. This study extends this discovery from the channel central line to the corner regions, and its general form of log-law was found to be valid even in trapezoidal or triangular
\end{abstract}

${ }^{1}$ Corresponding Author. 
open channels or closed ducts. This modified log-law can produce good agreement with the measured velocity with an average error of less than $5 \%$. Therefore, this study provides a simple and reliable tool for engineers and researchers to estimate the velocity contours in straight and smooth channel flows.

Keywords: velocity contours; closed duct; modified log-law; shear velocity; smooth open channel.

\section{Introduction}

Velocity distribution in channel flows is fundamentally important to simulate flow-related phenomena like pollution dispersion, sediment transport and flow-structure interaction. For 2D circular pipe flows, many pioneer researchers [1-6] have verified experimentally that the universal log-law is valid. After several attempts, the universal log-law [7, 8] has been empirically extended to non-circular pipe flows with different forms, which can be expressed in the following general form:

$$
\frac{u}{u_{* 1}}=\frac{1}{\kappa} \ln \frac{u_{* 2} y}{v}+B
$$

where, $\kappa=$ von Karman constant, $B=$ integral constant, $\frac{u}{u_{* 1}}$ and $\frac{u_{* 2} y}{v}$ are the dimensionless velocity $\mathrm{u}$ and distance $\mathrm{y}$, normalized by shear velocities $u_{* 1}$ and $u_{* 2}$, respectively, in which $y$ is the normal distance from the solid boundary and $v=$ kinematic viscosity. Based on his data from circular pipes reported by [9], where the local boundary shear stress = global average shear stress $=\rho g R S$, Nikuradse [9] recommended that $\kappa=0.4, B=5.52$ and $u_{* 1}=u_{* 2}=(\tau / \rho)^{0.5}$, in which $\tau=$ shear stress, $\rho=$ fluid density, $g=$ gravitational acceleration, $R=$ hydraulic radius, $S=$ energy slope.

However, when the applicability of log-law is extended to non-circular pipe flows, many experimental researchers found that there exist a wide scatter range in $\kappa$ and $B$. For instance, Laufer [10] observed $\kappa=0.34$ and $B=5.5$, Comte-Bellot [11] spotted $\kappa=0.40$ and $B=6.0$, 
Coantic [12] obtained $\kappa=0.40$ and $B=5.5$, and Zanoun, Durst and Nagib [13] found $\kappa=0.37$ and $B=3.7$. Now the mechanism responsible for these deviations is not clear yet.

Keulegan [14] was probably the first one who extended the log-law's application to open channel flows by assuming $u_{* 1}=u_{* 2}=u_{* 0}=(g R S)^{0.5}$. Several researchers in his time had found that the log-law could approximately express the measured velocity in the inner region and may extend to the outer region of channel flows $[6,15,16]$. Equation 1 with identical shear velocities on both side is termed the universal log-law and it has been widely used in numerical models. With the advent of sophisticated equipment and the accumulation of more experimental data, it is found that the universal log-law does not always perform well, but some modifications are needed to match the observed data. Coles [17] found that that the measured velocity is systematically higher than the log-law's prediction in all boundary layer flows, this deviation cannot be simply attributed to measurement errors, thus the wake-function is suggested for corrections. For channel flows, Buschmann and Gad-el-Hak [18] concluded that for the entire region, no specific law is valid, and Tracy and Lester [7] found that for central profiles of rectangular channels, a better agreement can be achieved if $u_{* 1}=(g R S)^{0.5}$ and $u_{* 2}$ $=(g h S)^{0.5}$ where $h$ is local water depth, and this claim has been supported by many experimental studies $[19,20]$.

Due to its importance, many researchers have investigated fully developed turbulent flows in pipes of noncircular cross sections [8,21-28]. Their results show that the velocity distribution is very complex and influenced by many factors like shape of cross section, aspect ratio, roughness distribution along the wetted perimeter, and non-uniform distribution of shear stress. The existing log-law cannot be simply applied to the corner region, and even in the central region, Tracy and Lester [7] observed that a better agreement between log-law's prediction and measured data can be achieved if different shear velocities are used to normalize the measured velocity and its distance. 
Keulegan [14] was the first one who realized that a flow region should be divided into subareas using its bisectors as shown in Fig. 1, in each sub-area he assumed that the log-law is valid, or the 3-D channel flow can be approximately treated as the 2-D flow. A similar idea has been proposed by Leighly [29] who divided the flow region into subregions using the orthogonals of the isovels (contours of mean velocity). Nevertheless, their treatments of flow region do not generate reliable outcomes when compared with the measured distribution of boundary shear stress and velocity [16]. Keulegan's [14] treatment implies that the local shear stress has no influence on the velocity and that it only depends on the global shear velocity. This assumption is contradicted with experimental data as noticed by Tracy and Lester [7], who concluded that the log-law can be improved using $u_{* 2}=(g h S)^{0.5}$, but they did not explain why and has no connection with the local boundary shear stress. In the 1990s, Yang and his coworkers [30-32] established a method to determine the boundary shear stress and it is found that the parameter $u_{* 2}$ in Tracy and Lester[7] equation is the local boundary shear stress, or more precisely with the boundary shear stress at the central point of channel flows. They proposed that the turbulent energy in any arbitrary flow volume will be transferred and dissipated on the nearest boundary [8]. For the trapezoidal duct in Fig. 1, one can divide the flow region into different sub-regions as Keulegan [14] suggested. Furthermore, based on the same principle, one can infer that the energy in the shaded area, $\Delta A$ will be transferred and dissipated on the wetted perimeter $\Delta p$ on the sidewall, and that the energy loss over a unit length in the streamwise direction is $\rho g \Delta A S$, and that the work done by friction force over the unit length is $\tau \Delta p$. From the energy conservation principle one has

$$
\tau=\rho g S \lim _{\Delta p \rightarrow 0} \frac{\Delta A}{\Delta p}=\rho g S l
$$

where $l=$ normal distance from the boundary to the division line or free surface where the Reynolds shear stress is zero [19, 33].

[Figure 1] 
After realizing that the parameter of $u *_{2}=(g h S)^{0.5}$ is the local shear velocity in Tracy and Lester's (1961) modified log-law, Yang et al. [34] inferred that the modified log-law can be extended into the corner region when

1) $u_{* 2}=(\tau / \rho)^{0.5}$ in Eq. 1 is used, and $\tau=$ the local boundary shear stress in the corner region.

2) Eq. 1 is applied along the boundary normal line $\left(l_{b}\right.$ and $\left.l_{w}\right)$ to the division line (dotted lines in Fig. 1).

However, Yang's inference has not been proved in other non-circular pipe flows like trapezoidal channels and rectangular ducts. As in numerical models, the log-law has been widely used as a boundary condition, but more attention should be paid to examine its validity using experimental data. The research objectives of this paper are:

1) To experimentally examine the validity of the modified log-law in the corner region, with more attention paid to the near boundary region;

2) To extend the application of Eq. 1 from rectangular channel flow to other flows with different shapes, especially closed ducts, and

3) To test whether the modified log-law can give a satisfactory prediction of velocity contours for engineering purposes.

\section{Background and Experiments}

\subsection{Theoretical considerations}

In fluid mechanics, to understand the turbulence structures, it is very important to find out the velocity distribution. For velocity contours in three-dimensional turbulent flow many researchers have presented different prediction methods. Unfortunately, even for the simplest channel flows, complex software is required to generate the velocity contour [35], which, irrespective of the complications, requires more time and effort than the average practising engineer can afford. Therefore, a simplified model to compute velocity contour would be more useful. 
Regardless of channel geometry, boundary shear stress is unequally distributed in three dimensional flows. It is generally agreed that non-uniform distribution of boundary shear stress has an important influence on velocity distribution [8]. The velocity distribution equation of von Karman-Prandtl is treated as the "law of the wall" of the logarithmic portion $[16,36]$, even it cannot provide reasonable velocity contours by following Keulegan's [14] suggestion, i.e., using mean shear velocity on both sides of the log-law.

Unlike Keulegan, Tracy and Lester [7] compared the log-law's performance by using different definitions, i.e., $u_{* 1}=u_{* 2}$ and $u_{* 1} \neq u_{* 2}$, and they concluded that if local shear velocity and global shear velocity are used to normalize the measured wall normal distance and near-wall velocity respectively, then the log-law's performance is enhanced significantly. But unfortunately their experimental data all come from the centre line of rectangular open channel flows, and only 10 measured profiles were used for the comparison.

Yang, et al. [8] linked the $u_{* 2}$ found by Tracy and Lester [7] with the local boundary shear stress, and the influence of local shear stress on the velocity was clarified. As the log-law has been used in numerical models as a boundary condition, it is necessary to examine the modified log-law's performance in the near boundary region. In Tracy and Lester's [7] experiment, a propeller (intrusive to flow) was used to measure the velocity and now measurement accuracy can be significantly improved using the modern Laser-Doppler Velocimeter (LDV) which can measure (non-intrusive to flow) the velocity very close to the boundary, thus such an experiment is useful to clarify the validity of the modified log-law.

According to Yang, et al. [8], the modified log-law can be extended to the corner region, this enlarges the log-law's application, and even the data from rectangular open channels have been used for verification. Further it is still needed to investigate whether the log-law can generate satisfactory velocity in other channels like rectangular, trapezoidal, triangular using, $u_{* 1}=$ 
global shear velocity $=\sqrt{g R S}$ and $u_{* 2}=$ local boundary shear velocity $=\sqrt{g l_{n} S}$, where $l_{n}$ is the distance normal to the boundary ( $l_{b}$, bed or $l_{w}$, wall in Fig. 1).

\subsection{Experimental setup}

In this study, experiments were performed at the hydraulics laboratory of the University of Wollongong. The flume was $10.5 \mathrm{~m}$ long and had a straight rectangular cross-section constructed from 12-mm thick polished float glass, which has low Manning roughness coefficient of 0.01[37], (see Fig. 2a and 2b). At the entrance of the flume, a honeycomb with a size of $300 \mathrm{~mm}$ long, $250 \mathrm{~mm}$ high and $287 \mathrm{~mm}$ wide was glued by silicone between the flume walls and a series of baffles in a staggered configuration (Fig. 2c). The flow in the flume was generated through a $35 \mathrm{~L} / \mathrm{s}$ automated pump connected to a large overhead water tank (for more details, see Han, Yang, Sivakumar and Qiu [38]). The water depth through the flume was controlled by an adjustable tailgate in the downstream tail tank. The relative height of this tailgate was adjusted by rotating the attached handle.

The location of the measurement section was $6 \mathrm{~m}$ from the inlet of the flume. For all test conditions, the maximum turbulence intensity occurs very close to the bed. Moreover, from the bed to the inner layer, the turbulence intensity decreases up to a certain value, then remains almost constant towards the free surface. Turbulence intensity is found to be less than $2 \%$ at the measurement location. Flow depths were measured using point gauges with an accuracy of $\pm 0.1 \mathrm{~mm}$. The depth of water could be adjusted by controlling the tailgate located in the collection tank at the downstream end of the flume. To attain steady and uniform flow conditions, the water surface slope and the flume bed slope were kept constant in each experiment and were repeatedly checked before the data collection. Table 1 summarizes the hydraulic parameters for the flow measurements during laboratory experiments that were chosen after a lot of trials until it was ensured that fully developed flow conditions had been 
Journal of Fluids Engineering

achieved. All experiments were conducted in steady uniform and fully developed turbulent flows at Reynolds number at 127000 and 129000.

\section{[Table 1]}

In this study, a Laser Doppler Velocimeter (LDV) was used to measure point velocities during the experiments. It is a two component configuration with a $60 \mathrm{~mm}$ optical fibre probe and a lens of $400 \mathrm{~mm}$ focal length. The probe was aligned normal to the $\mathrm{x}$-axis. Dantec polyamid seeding particles of 20 and $50 \mu \mathrm{m}$ diameter (PSP-50, diam. $50 \mu \mathrm{m}$ and PSP-20, diam. $20 \mu \mathrm{m}$ ) were seeded in the flume. It is important to note that, during the measurement of velocity by LDA, data acquisition of the components needed to be coincidental in time for all the data pairs. The signal processor is a Dantec Burst Spectrum Analyser (BSA) connected to an oscilloscope and a PC. The BSA converts the electrical signals, which are processed by the oscilloscope, into velocity data, which again are monitored online by a PC. Raw data exported from the BSA can be processed into statistical values like mean velocities, root mean squared values of velocity fluctuations, and Reynolds stresses.

The sampling rate varied point by point from bed to the water surface, and it generally ranged up to $100 \mathrm{~Hz}$. Velocity measurements were averaged over 2000 data points collected at single points at equal intervals of $10 \mathrm{~ms}$ to yield a time of averaging of $20 \mathrm{~s}$. Bias error in the velocity measurements was small. Velocity bias was eliminated by operating the system at high signal rates and properly time averaging the processor output. Concentration bias was not a factor during present experiments, since the water was uniformly seeded. Experimental uncertainties were found to be less than $2 \%$ for streamwise mean-velocity measurements and $4 \%$ for the root mean square (RMS) velocity fluctuation measurements.

\section{[Figure 2]}

\section{Analysis of Experimental Results}

\subsection{Experimental results}


For the smooth rectangular channel, the main flow section can be divided to calculate the velocity contours as shown in Fig. 2(b). The flow region is divided by the division lines into three sub-regions, OCGD in Fig. 2(b) for the bed region, and similarly OAC and DBG for the side wall regions. The dotted lines represent the division lines and the dash lines represent the boundary shear stress distribution for the smooth rectangular channel, where $l_{w}=\mathrm{z}$ and $l_{b}=\mathrm{y}$ and $l=$ normal distance to the nearest boundary. For the bed region, the local shear velocity was calculated by using $l_{b}$ and for the wall regions the local shear velocities were calculated using $l_{w}$, where $l_{b}$ and $l_{w}$ are the normal distances from the boundary to the division line or free surface. Velocity contours of channel flows with $\operatorname{Re}=1.27 \times 10^{5}$ and $\operatorname{Re}=1.92 \times 10^{5}$ are shown in figure 3 (a) and 4 (a) for aspect ratios of 2.22 and 3.45, respectively. To examine the modified log-law, the velocity contours are calculated using Eq. 1 and the results are shown in Figs $(3,4$ b). It can be seen that isovel contours of calculated agree with the measured contours well, indicating that Eq. (1) is reliable for calculating the point velocity distribution. To validate the modified log-law, the relative error between measured and calculated isovelocity contours was obtained from $\mathrm{E}=\frac{\left|u_{c}-u_{m}\right|}{u_{m}} \times 100 \%$ where $u_{c}$ is the calculated velocity and $u_{m}$ is the measured velocity. The overall relative error in the calculated velocity contours is $5.09 \%$ but it is different for each profile indicated as $7.23 \%, 7.92 \%, 5.11 \%, 5.70 \%, 3.22 \%$, and 1.35 $\%$ respectively from near wall contour towards the centre of the channel. The measured velocity distribution contours are much closer to the calculated contours and the estimation is within the acceptable range.

\section{[Figure 3]}

\section{[Figure 4]}

In Tracy and Lester's [7] experiment, the velocity very close to the boundary was unable to obtained due to the equipment incapacity, thus the validity of the modified log-law in the inner region of 3-D flows for a smooth channel has not been verified fully. Figure 5 shows typical 
results of measured mean velocity distribution in the bed region for $\mathrm{b} / \mathrm{h}=3.45$ (test 2 ). It can be seen from Fig. 5 that, each velocity profile has a different intercept while, near the wall region velocities are represented by straight parallel lines. In general, the agreement between the modified log-law and the near boundary velocity is acceptable.

It is noticeable from Figure 5 that at a certain distance the linear relationship converge and surplus energy is transferred towards the bed not towards the side wall. In a horizontal profile this occurs when the measuring point exceeds the division lines as shown in Fig 2(b) and in simple words it indicates that velocities belong to two different sub-sections as near bed region or near wall region separated by divisional lines DG and OC. Figure 5 shows that the slopes of the parallel lines resemble each other, which indicates that $u_{* 1}$ is constant in Eq. (1), and this confirms Tracy and Lester's (1961) finding. The different intercepts clearly indicate that $u_{* 2}$ in Eq. 1 should be different for different profiles, which confirms that the $u_{* 2}$ is not the same for each profile. It is necessary to examine whether the expression of $u *_{2}=(\tau / \rho)^{0.5}$ is appropriate and the intercept is really related to the local shear stress obtained by Yang and $\operatorname{Lim}[31]$.

\section{[Figure 5]}

The velocity profiles were measured across the flow section at eight verticals, i.e., $z=10,20$, $30,60,70,90,110,130 \mathrm{~mm}$, respectively. Figure 6 shows the velocity distribution in the bed region (see Fig. 2b) in a plot of $\frac{u}{u_{* 1}}$ against dimensionless distance $\frac{u_{* 2} y}{v}$. It is interesting to note that all data points collapse into a single line that can be represented by the modified log-law where $k=0.4$ and $B=5.52$ remain unchanged. This is clear from Fig. 6 by plotting the data using two different shear velocities, $u_{* 1}$ as global shear velocity and $u_{* 2}$ as local boundary shear velocity. The data points have a single relationship and collapse in a single line which confirms the discovery of Tracy and Lester [7] and Yang, et al. [8] who found that, while using the same shear velocities on both side of the law of wall. Yang, et al. [8] obtained local shear 
Journal of Fluids Engineering

velocity using two sub regions i.e. sidewall and bed, and concluded that the log law does not produce good results when using the same shear velocities.

\section{[Figure 6]}

\subsection{Verification of the modified Log-Law using data from duct flows:}

Technically, to model velocity accurately, one needs to solve three problems:

1) The determination of boundary shear stress distribution $\tau$ or its alternative form $u_{*} ; 2$ ) to determine whether the connection of velocity and its shear velocity and the log-law or its modified form is accepted; and 3) the application limit of the log-law.

The shear velocity $u_{*}$ is one of the most disputed and vague parameters in fluid mechanics. This is the most fundamental velocity scale, which can be used to normalize mean velocity and turbulence intensity. Most researchers have argued that use of $u_{* r}$ (calculated from Reynolds shear stress) or $u_{* v}$ (calculated from the viscous sub layer) is most accurate for use on both side of the log law equation in comparison to the other methods [39-43]. It has been assumed in literature $[7,24,39,40,44]$ without adequate justification from experimental data that $u_{* 1}=$ $u_{* 2}=$ local shear velocity. A simple way to judge this is to observe whether the predicted velocity contours agree with the measured contours. Currently, for noncircular cross-sectional duct flows in the literature, to the authors' best knowledge, none of the researchers has investigated whether reasonable velocity contours can be modelled by the modified log-law where both global shear velocity and local boundary shear velocity are used simultaneously.

To examine Yang's concept for smooth ducts, the velocity contours measured by Khalifa and Trupp [24], Nikuradse [9], and Prinos, Tavouiaris and Townsend [28] are used for comparison in this study. The duct used by Khalifa and Trupp [24] had dimensions of the cross-section of $\mathrm{AB}=2.54 \mathrm{~cm}, \mathrm{BC}=6.6 \mathrm{~cm}, \mathrm{CD}=6.35 \mathrm{~cm}$ (see Fig. 1). They measured isovel contours of the trapezoidal duct using a Pitot tube (intrusive to flow) and the result is shown in Fig. 7(a). To calculate the contours the duct was divided in three sub regions, i.e., for wall AOD and BAOG 
Journal of Fluids Engineering

and for bed CDOG. Furthermore, the regions BAOG and CDOG were further sub divided, as normal distance from OG to either side of the duct is equal. For region OG to either side of the duct, the point velocity is calculated using the distance from the bed towards the centre of the duct. For this region, the error is indicated as $6.55 \%, 3.45 \%, 5.35 \%, 0.10 \%$, and $1.64 \%$ from bed towards the centre of the duct between calculated and measured point velocities. Likewise, qualitatively both are in good agreement, whilst the calculated isovel contours using the modified log-law are shown in Fig. 7(b).

\section{[Figure 7]}

Similarly, the curves of constant velocity distribution for a smooth triangular cross-sectional duct obtained by Nikuradse [9] are as shown in Fig. (8). The measured contours are shown in Fig. 8 (a) and the calculated contours of isovelocity using Eq. (1) are shown in Fig. 8 (b); both are in fairly good agreement. The error between the calculated and measured velocity contours for each profile is indicated as $0.7 \%, 2.9 \%, 1.7 \%, 3.4 \%, 2.3 \%$, and $1.9 \%$ respectively from near wall or bed contour towards the centre of the duct.

\section{[Figure 8]}

Nikuradse [9] plotted isovel contours for a rectangular duct by experimental data as shown in Fig. (9), which shows the comparison between the measured and calculated velocity contours in the smooth rectangular duct. It can be seen that the agreement between measured and calculated velocities is acceptable.

\section{[Figure 9]}

\subsection{Discussion}

Based on the comparison shown in Figs. (3-4 and 7-9), one can see that the modified Eq. (1) can be extended to non-circular channel flows, i.e., rectangular channels, trapezoidal, triangular and rectangular ducts. Table 2 shows, the measured and calculated velocity distribution averaged relative error (E) as; $4.18 \%, 2.13 \%$, and $3.47 \%$ for trapezoidal, triangular and 
Journal of Fluids Engineering

rectangular ducts respectively. Good agreement between measured and calculated pointvelocity indicates that the Eq. (1) is also applicable to different types of non-circular crosssectional ducts (conduits) when different shear velocities i.e., $u_{* 1}(=\sqrt{g R S})$ and $u_{* 2}=\sqrt{g h S}$ $=$ the local boundary shear velocity are used to normalize $u$ and $y$, respectively. The variation in $\mathrm{E}$ in the present study may be due to secondary currents, and measurement error. Nikuradse [9] first observed that the secondary flows arising in the simplest geometry were in a straight square or rectangular cross-sectional duct. Furthermore, it was reported that the contours of mean isovelocity bulged near the corners outwards due to secondary motion from the centre towards the corners of the ducts as clearly shown in Figure 7 and Figure 10.

\section{[Figure 10]}

\section{[Table 2]}

Nezu and Nakagawa [45] and Nezu and Rodi [46] were the first ones to experimentally observe that the secondary currents of open channel and closed ducts are quite different and would be attributed to the effect of side wall, free surface and change in bed topology. As Figure 10 shows, secondary currents have a relatively strong effect in the corner regions. Furthermore, this study only investigates the velocity distribution in smooth straight channel/ducts in fully developed turbulent flow region. As shown in Figure 10, Prinos, et al. [28] performed experiments in a $12 \mathrm{~m}$ long straight duct with $154 \mathrm{~mm}$ hydraulic diameter (D). Most of the measurements were taken at a location near the flume inlet that was not fully developed and the calculated isovelocity contours in the developing region of the cross section showed strong asymmetry (see Figs. 10a and 10b). As error in left side of top wall region from wall towards centre of the duct is greater than $20 \%$ and along the top right corner from top wall and side wall towards centre, the error is greater than $15 \%$. Both velocity distribution and wall shear stress distribution are majorly affected by secondary currents associated with section nonaxisymmetry. It is noteworthy that the effect of secondary flow is less significant in fully 
Journal of Fluids Engineering

developed straight non-circular duct flow (see Figures 8 and 9), as a straight noncircular cross section duct has no secondary currents [47]. Subsequently, it could be observed that the developing flow is much more sensitive to inlet condition than the fully developed flow as shown in Fig. 10 (a) and ultimately the calculation by Eq. (1) showed asymmetry with the measured isovel contours shown in Fig. 10 (b), which shows that due to secondary currents the maximum velocity occurs approximately half way between the centre and the side wall and isovel patterns are strongly affected by the relatively high secondary current in developing flows. The wall shear stress is significantly less in the fully developed region whereas, at the inlet of the duct, the wall shear stress is significantly the highest because at the entrance region boundary layers have the least thickness. As measurements were taken in developing flow, where strong secondary currents occur and Fig. 10 (a) and Fig. 10 (b) show difference in velocity contour plot, this clearly establishes that Eq. (1) is valid and obtains reasonable isovelocity contours in symmetry only for fully developed smooth duct flows. We can apply this approach only for the smooth and straight narrow channels i.e., rectangular, triangular and trapezoidal in clear water. Furthermore, this method is only applicable to fully developed flow region.

\section{Conclusion}

Different from sophisticated numerical software, this study examine the validity of modified log-law to model 3-D velocity in straight and smooth channel flows, in which the global shear velocity to normalize the point velocity, i.e., $u^{+}$, the local shear velocity is used to normalize the dimensionless normal distance, i.e., $y^{+}$. In this study, performance of the modified log-law is examined in a smooth surface rectangular, trapezoidal, and triangular open or closed channel. Because the local and global boundary shear stresses are identical for circular pipe flows, the modified log-law becomes the classical log-law. On the other hand, for all non-circular pipe flows, the local boundary shear stress is different from the overall or global shear stress. This 
Journal of Fluids Engineering

study applies Yang's method to determine the local boundary shear stress, which assumes that the cross-sectional area of flow in open channels and closed ducts can be subdivided into infinite sub-regions. This study demonstrates that the measured velocity can be effectively estimated by using the modified log-law for each sub-region (i.e., bed and sidewall region). Notably, this study validates the conclusion reported by Tracy and Lester that the modified loglaw can achieve a good agreement for the central profile for rectangular channels. Furthermore, this study also demonstrates that the velocity in corner regions can be predicted by using the modified log-law when the local shear velocity is used to normalize the distance in subregions. The findings of this study confirms that the modified log-law is valid for expressing the velocity contours in rectangular, trapezoidal and triangular channels. This simple model is flexible, and the effect of channel shape is well-captured without the need of an empirical parameter. Hence, the modified log-law provides a simple but flexible way for engineers, particularly numerical modellers, who need a reliable way to calibrate their numerical models. As the log-law is widely considered as a universal law, more investigations are needed in future to verify the validity of the modified log-law for non-uniform and rough channels.

\section{ACKNOWLEDGMENT}

The second author wish to acknowledge the joint $\mathrm{PhD}$ scholarship provided by Higher Education Commission (HEC) of Pakistan and University of Wollongong, Australia. The second author also would like to express his very great appreciation to Mrs Huda Zain and Mr Muhammad Bilal Asif for their valuable suggestions. 


\section{REFERENCES}

[1] Millikan, C. B., "A critical discussion of turbulent flow in channels and circular tubes," Proc. 5th Int. Congress on Applied Mechanics (Cambridge, MA, 1938), Wiley, pp. 386-392.

[2] Nikuradse, J., 1933, "Gesetzmäßigkeiten der turbulenten Strömung in glatten Rohren (Nachtrag)," Forschung im Ingenieurwesen, 4(1), pp. 44-44.

[3] Prandtl, L., 1925, "Bericht uber Untersuchungen zur ausgebildeten Turbulenz," Zs. angew. Math. Mech., 5, pp. 136-139.

[4] Rotta, J., 1962, "Turbulent boundary layers in incompressible flow," Prog. Aero. Sci., p. 46.

[5] Townsend, A. A., 1980, The structure of turbulent shear flow, Cambridge university press.

[6] Von Kármán, T., 1930, "Mechanische ahnlichkeit und turbulenz," Math.-Phys. Klasse.

[7] Tracy, H. J., and Lester, C., 1961, Resistance coefficients and velocity distribution smooth rectangular channel, US Government Printing Office.

[8] Yang, S.-Q., Lim, S.-Y., and McCorquodale, J., 2005, "Investigation of near wall velocity in 3-D smooth channel flows," Journal of Hydraulic Research, 43(2), pp. 149-157.

[9] Nikuradse, J., 1926, "Untersuchungen Uber die Geschwindigkeits-verteilung in turbulenten Stromungen VDI," Forschungsheft, 291.

[10] Laufer, J., 1954, "The structure of turbulence in fully developed pipe flow," Rep. 1174, Natl. Adv. Comm. for Aeronaut., Washington, D.C.

[11] Comte-Bellot, G., 1963, "Contribution à l'étude de la turbulence de conduite," These Presente a la Faculte des Sciences de l'Universite de Grenoble.

[12] Coantic, M., 1966, "Contribution à l'étude de la structure de la turbulence dans une conduite de section circulaire," Univ. Aix-Marseille., Thesis de Doctorat $\sim \mathrm{s}-$ Sciences Physiques.

[13] Zanoun, E.-S., Durst, F., and Nagib, H., 2003, "Evaluating the law of the wall in twodimensional fully developed turbulent channel flows," Physics of Fluids, 15(10), pp. 30793089 .

[14] Keulegan, G. H., 1938, Laws of turbulent flow in open channels, National Bureau of Standards US.

[15] Prandtl, L., 1933, "Neuere ergebnisse der turbulenzforschung," VDI-Ztschr, 77(5), p. 105.

[16] Nezu, I., and Nakagawa, H., 1993, "Turbulence in open channels," IAHR/AIRH Monograph. Balkema, Rotterdam, The Netherlands.

[17] Coles, D., 1956, "The law of the wake in the turbulent boundary layer," Journal of Fluid Mechanics, 1(2), pp. 191-226.

[18] Buschmann, M. H., and Gad-el-Hak, M., 2003, "Debate concerning the mean-velocity profile of a turbulent boundary layer," AIAA journal, 41(4), pp. 565-572.

[19] Han, Y., Yang, S.-Q., Dharmasiri, N., and Sivakumar, M., 2014, "Experimental study of smooth channel flow division based on velocity distribution," Journal of Hydraulic Engineering, 141(4), p. 06014025. 
[20] Yang, S.-Q., and McCorquodale, J. A., 2004, "Determination of boundary shear stress and Reynolds shear stress in smooth rectangular channel flows," Journal of hydraulic engineering, 130(5), pp. 458-462.

[21] Afzal, N., and Seena, A., 2018, "Mean Velocity, Reynolds Shear Stress, and Fluctuations of Velocity and Pressure Due to Log Laws in a Turbulent Boundary Layer and Origin Offset by Prandtl Transposition Theorem," Journal of Fluids Engineering, 140(7), pp. 071204071204-071223.

[22] Berlamont, J. E., Trouw, K., and Luyckx, G., 2003, "Shear stress distribution in partially filled pipes," Journal of Hydraulic Engineering, 129(9), pp. 697-705.

[23] Jin, Y.-C., Zarrati, A., and Zheng, Y., 2004, "Boundary shear distribution in straight ducts and open channels," Journal of Hydraulic Engineering, 130(9), pp. 924-928.

[24] Khalifa, M., and Trupp, A., 1988, "Measurements of fully developed turbulent flow in a trapezoidal duct," Experiments in fluids, 6(5), pp. 344-352.

[25] Knight, D. W., and Patel, H. S., 1985, "Boundary shear in smooth rectangular ducts," Journal of Hydraulic Engineering, 111(1), pp. 29-47.

[26] Melling, A. J., 1975, "Investigation of flow in non-circular ducts and other configurations by laser Doppler anemometry," University of London.

[27] Nikuradse, J., 1930, "Untersuchungen über turbulente Strömungen in nicht kreisförmigen Rohren," Ingenieur-Archiv, 1(3), pp. 306-332.

[28] Prinos, P., Tavouiaris, S., and Townsend, R., 1988, "Turbulence measurements in smooth and rough-walled trapezoidal ducts," Journal of Hydraulic Engineering, 114(1), pp. 43-53.

[29] Leighly, J. B., 1932, Toward a theory of the morphologic significance of turbulence in the flow of water in streams, University of California Press.

[30] Yang, S., 1993, "The Law of Boundary Shear in Open Rectangular Channels [J]," Journal of Sediment Research, 3, p. 012.

[31] Yang, S.-Q., and Lim, S.-Y., 1997, "Mechanism of energy transportation and turbulent flow in a 3D channel," Journal of Hydraulic Engineering, 123(8), pp. 684-692.

[32] Yang, S.-Q., and Lim, S.-Y., 1998, "Boundary shear stress distributions in smooth rectangular open channel flows," Proceedings of the Institution of Civil Engineers. Water, maritime and energy, 130(3), pp. 163-173.

[33] Yang, S.-Q., Han, Y., Lin, P., Jiang, C., and Walker, R., 2014, "Experimental study on the validity of flow region division," Journal of Hydro-environment Research, 8(4), pp. 421-427.

[34] Lim, S.-Y., and Yang, S.-Q., 2005, "Simplified model of tractive-force distribution in closed conduits," Journal of Hydraulic Engineering, 131(4), pp. 322-329.

[35] Wang, C., 2018, "Fully-Developed Flow in Semicircular and Isosceles Triangular Ducts With Nonuniform Slip," Journal of Fluids Engineering, 140(12), p. 121302.

[36] Schlichting, H., Kestin, J., and Street, R. L., 1980, "Boundary-Layer Theory," American Society of Mechanical Engineers. 
[37] Han, Y., 2014, "Experimental verification of flow divisibility in 3-D laboratory channels," Doctor of Philosophy thesis, School of Civil, Mining, and Environmental Engineering, University of Wollongong.

[38] Han, Y., Yang, S.-Q., Sivakumar, M., and Qiu, L.-C., 2017, "Investigation of velocity distribution in open channel flows based on conditional average of turbulent structures," Mathematical Problems in Engineering, 2017.

[39] Auel, C., Albayrak, I., and Boes, R. M., 2013, "Turbulence characteristics in supercritical open channel flows: effects of Froude number and aspect ratio," Journal of Hydraulic Engineering, 140(4), p. 04014004.

[40] Kirkgöz, M. S., 1989, "Turbulent velocity profiles for smooth and rough open channel flow," Journal of Hydraulic Engineering, 115(11), pp. 1543-1561.

[41] Kirkgöz, M. S., and Ardiçlioğlu, M., 1997, "Velocity profiles of developing and developed open channel flow," Journal of Hydraulic Engineering, 123(12), pp. 1099-1105.

[42] Roussinova, V., 2009, "Turbulent structures in smooth and rough open channel flows: effect of depth," Electronic Theses and Dissertations. 94.

[43] Sarkar, S., 2016, "Measurement of turbulent flow in a narrow open channel," Journal of Hydrology and Hydromechanics, 64(3), pp. 273-280.

[44] Cardoso, A., Graf, W. H., and Gust, G., 1989, "Uniform flow in a smooth open channel," Journal of Hydraulic Research, 27(5), pp. 603-616.

[45] Nezu, I., and Nakagawa, H., 1984, "Cellular secondary currents in straight conduit," Journal of hydraulic engineering, 110(2), pp. 173-193.

[46] Nezu, I., and Rodi, W., 1986, "Open-channel flow measurements with a laser Doppler anemometer," Journal of Hydraulic Engineering, 112(5), pp. 335-355.

[47] White, F., 1979, "Fluid Mechanics, International Student Edition," McGraw Hill Inc.: Columbus, $\mathrm{OH}$, USA. 


\section{Figure Captions List}

Figure 1. Definition sketch and local boundary shear stress distribution for trapezoidal duct.

Figure 2. (a) Schematic diagram of the laboratory flume; (b) View of flume crosssection; (c) Experimental set-up arrangement. All dimensions are in meters (m).

Figure 3. (a) Isovel contours of mean velocity measured in smooth rectangular channel for $\mathrm{b} / \mathrm{h}=2.22$, (b) Calculated Isovel contours using Eq. (1) where $u_{* 1}=$ global boundary shear velocity and $u_{* 2}=(\tau / \rho)^{0.5}$.

Figure 4. (a) Isovel contours of mean velocity measured in smooth rectangular channel for $\mathrm{b} / \mathrm{h}=3.45$, (b) Calculated Isovel contours using Eq. (1) where $u_{* 1}=$ global boundary shear velocity and $u_{* 2}=(\tau / \rho)^{0.5}$.

Figure 5. In bed region typical horizontal velocity distribution for test 2.

Figure 6. Dimensionless velocity distribution with $\frac{u}{u_{* 1}}$ versus $\frac{u_{* 2} y}{v}$ in bed region.

Figure 7. Comparison between measured velocity contours and calculated by Eq. (1) in a trapezoidal duct $\left(\phi=60^{\circ}\right)$. The measured velocity contours (a) are based on Khalifa and Trupp [24], while calculated velocity contours (b) are estimated by using the modified law-log law in the current study.

Figure 8. Comparison between measured and calculated velocity contours in triangular duct using Eq. (1). The measured velocity contours (a) are based on Nikuradse [9], while calculated velocity contours (b) are estimated by using the modified law-log law in the current study.

Figure 9. Comparison of measured isovelocity contours in rectangular duct. The measured velocity contours (a) are based on Nikuradse [9], while calculated 
Journal of Fluids Engineering

velocity contours (b) are estimated by using the modified law-log law in the current study.

Figure 10. Comparison of measured isovelocity contours in a trapezoidal duct (corner angles were $60^{\circ}$ and $116^{\circ}$ ). The measured velocity contours (a) are based on Prinos et al. [29], while calculated velocity contours (b) are estimated by using the modified law-log law in the current study. 
Journal of Fluids Engineering

\section{Table Captions List}

Table 1: Summary of hydraulic parameters used in experiments.

Table 2: Averaged relative error of point velocity contours. 


\section{List of Figures}

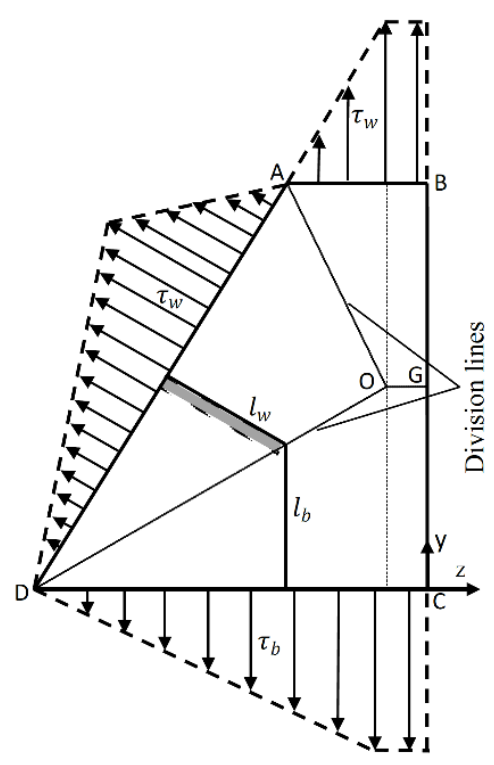

Figure 1. Definition sketch and local boundary shear stress distribution for trapezoidal duct. 

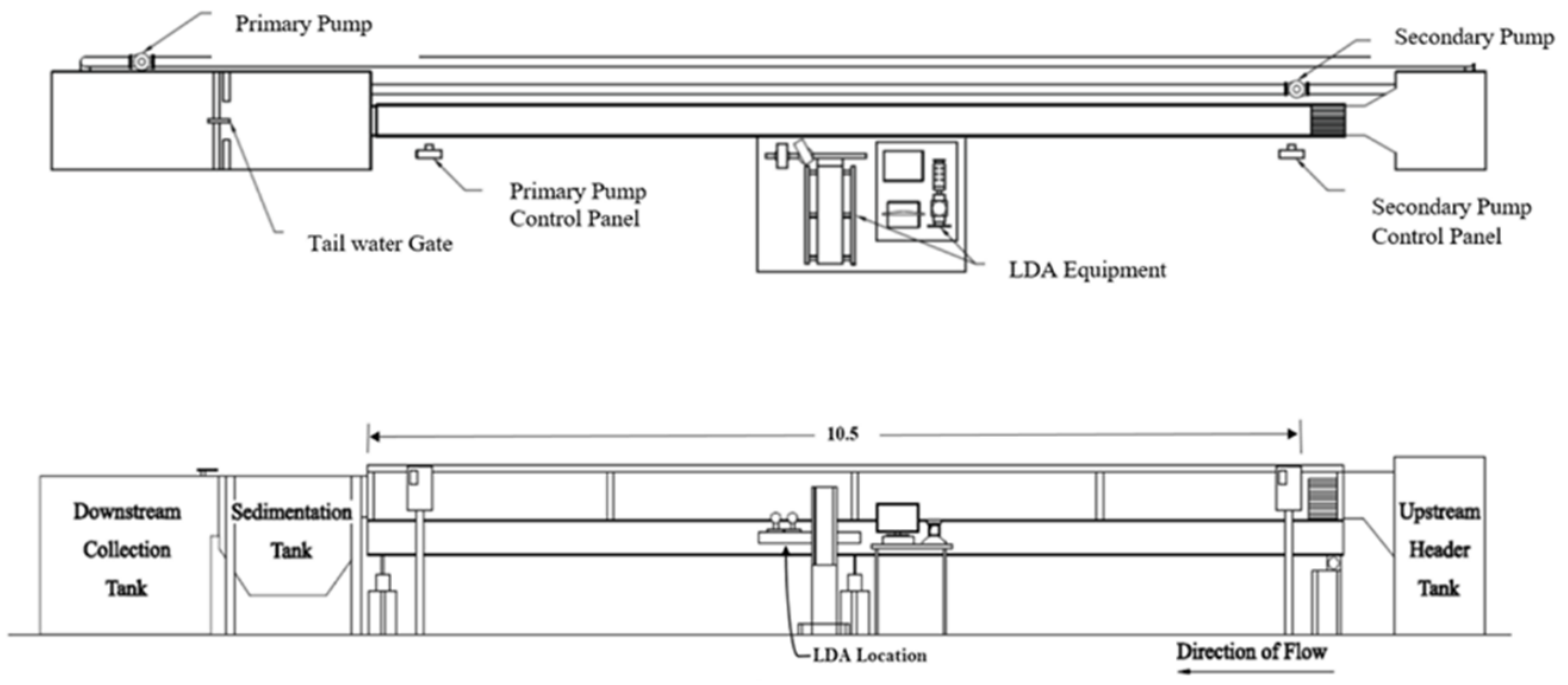

(a)

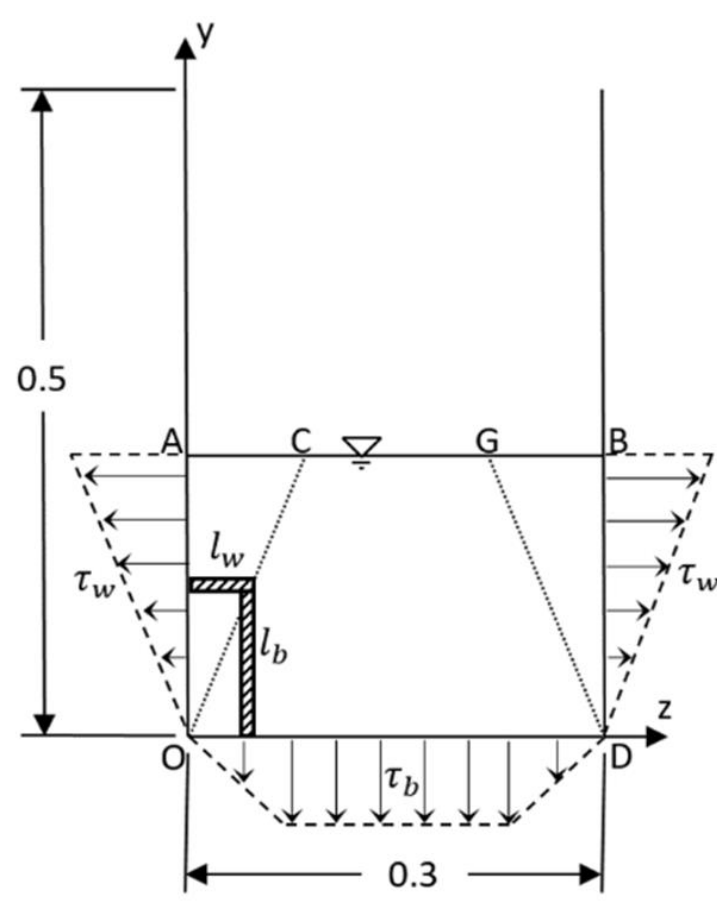

(b)

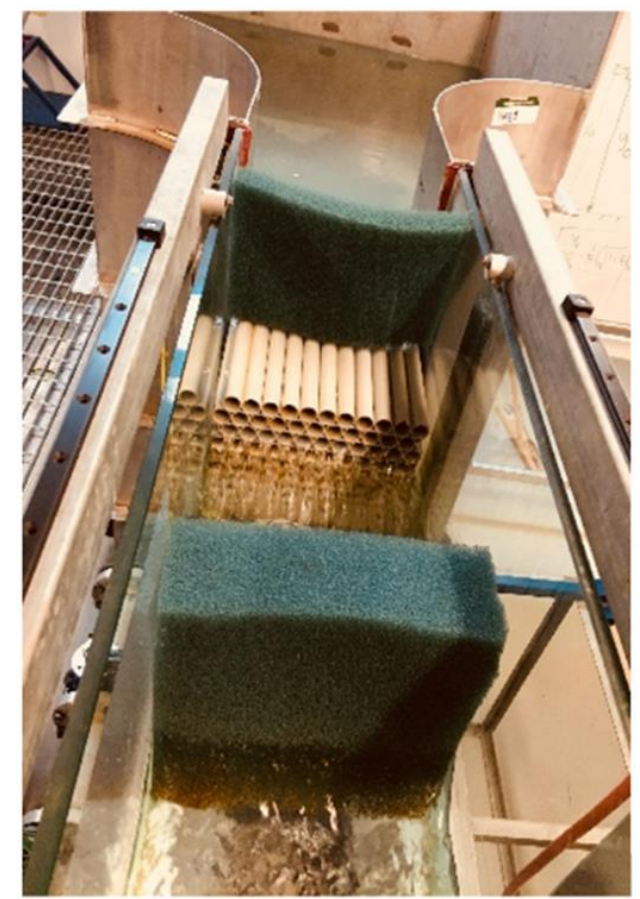

(c)

Figure 2. (a) Schematic diagram of the laboratory flume; (b) View of flume cross-section; (c) Experimental set-up arrangement. All dimensions are in meters (m). 


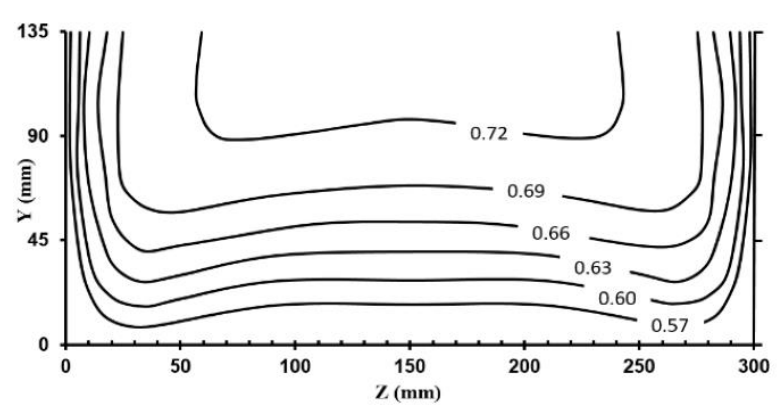

(a) Measured

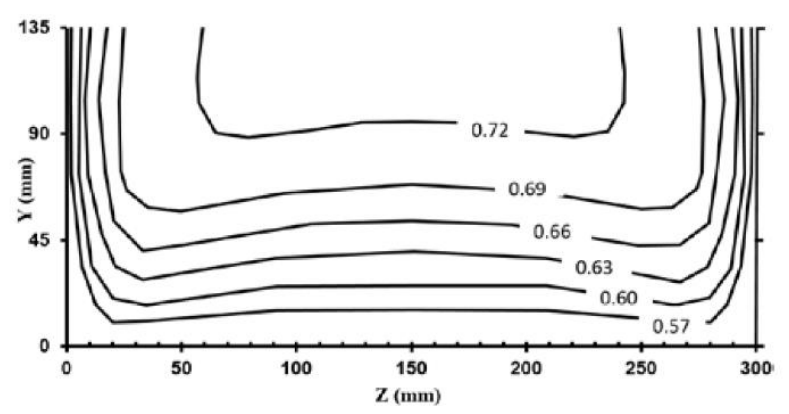

(b) Calculated

Figure 3. (a) Isovel Contours of mean velocity measured in smooth rectangular channel for $\mathrm{b} / \mathrm{h}=2.22$, (b) Calculated Isovel contours using Eq. (1) where $u_{* 1}=$ global boundary shear velocity and $u_{* 2}=(\tau / \rho)^{0.5}$. 


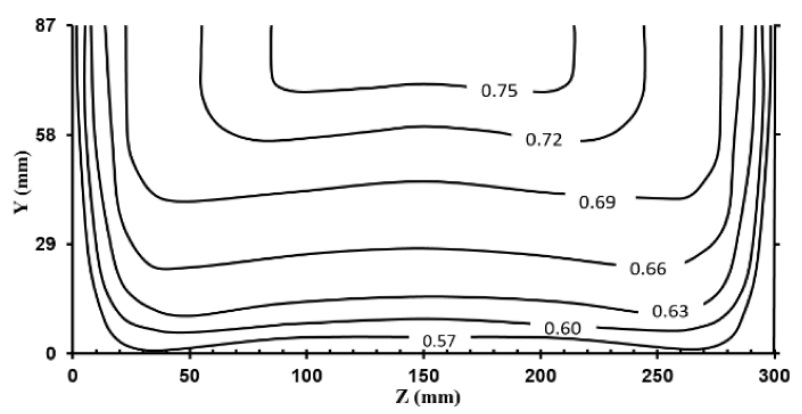

(a) Measured

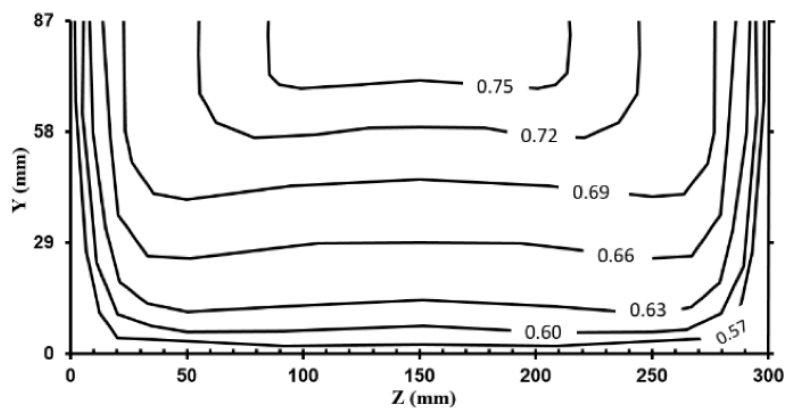

(b) Calculated

Figure 4. (a) Isovel Contours of mean velocity measured in smooth rectangular channel for $\mathrm{b} / \mathrm{h}=3.45$, (b) Calculated Isovel contours using Eq. (1) where $u_{* 1}=$ global boundary shear velocity and $u_{* 2}=(\tau / \rho)^{0.5}$. 


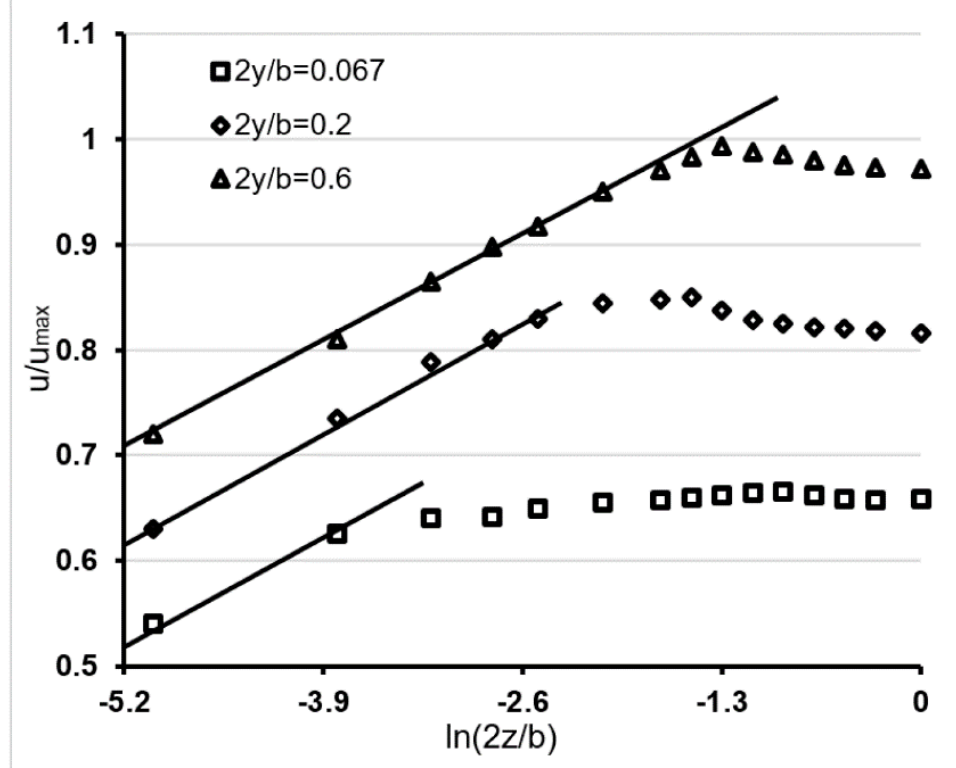

Figure 5. In bed region typical horizontal velocity distribution for test 2 . 
Journal of Fluids Engineering

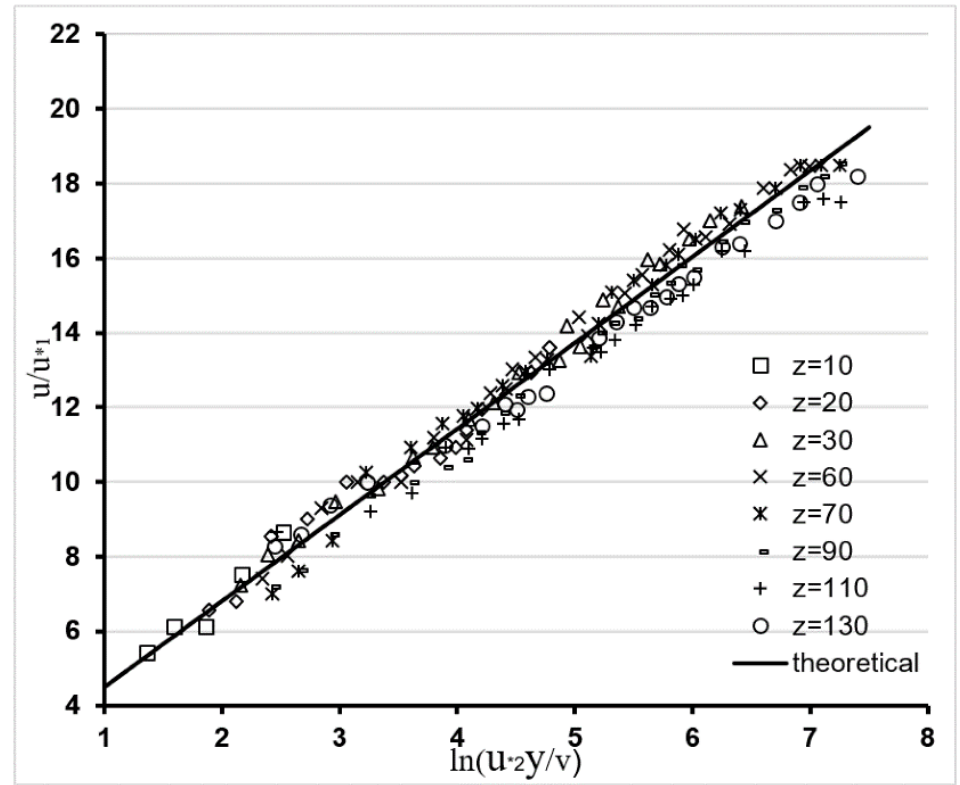

Figure 6. Dimensionless velocity distribution with $\frac{u}{u_{* 1}}$ versus $\frac{u_{* 2} y}{v}$ in bed region. 


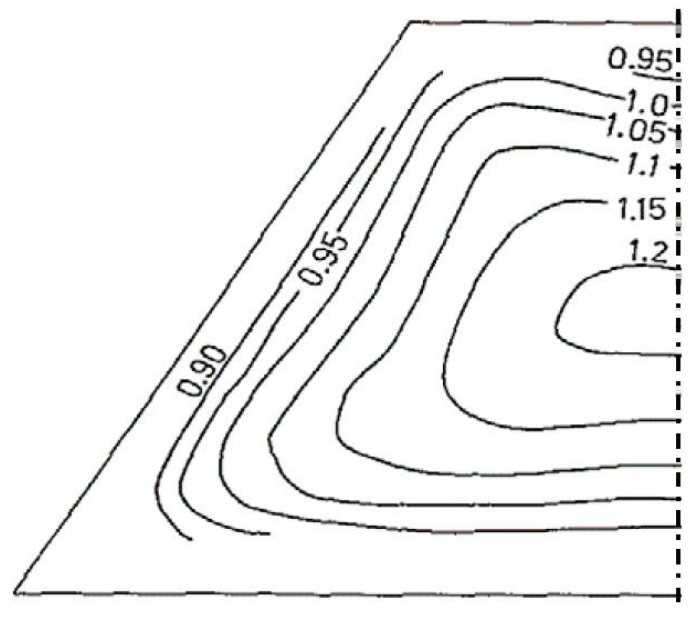

(a) Measured

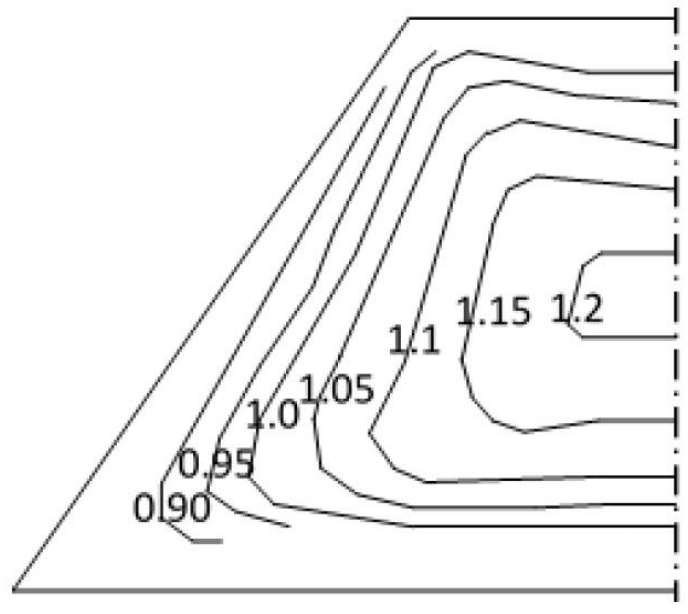

(b) Calculated

Figure 7. Comparison between measured velocity contours and calculated by Eq. (1) in a trapezoidal duct $\left(\phi=60^{\circ}\right)$. The measured velocity contours (a) are based on Khalifa and Trupp [24], while calculated velocity contours (b) are estimated by using the modified law$\log$ law in the current study. 


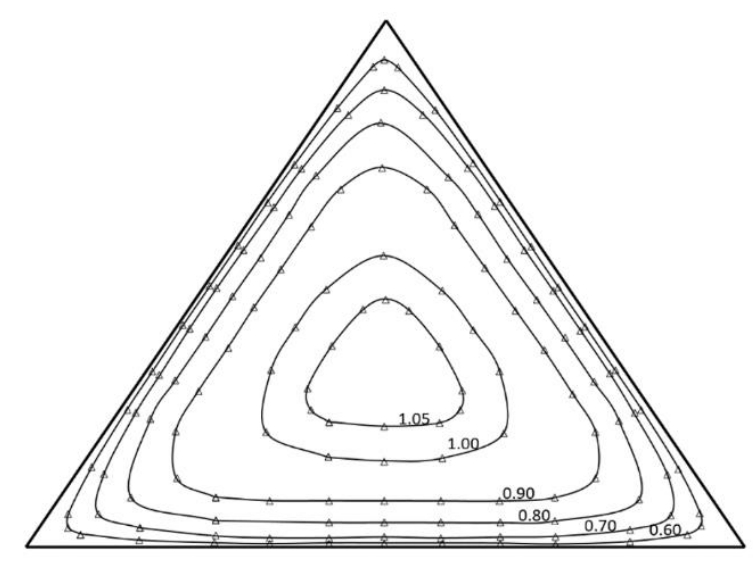

(a) Measured

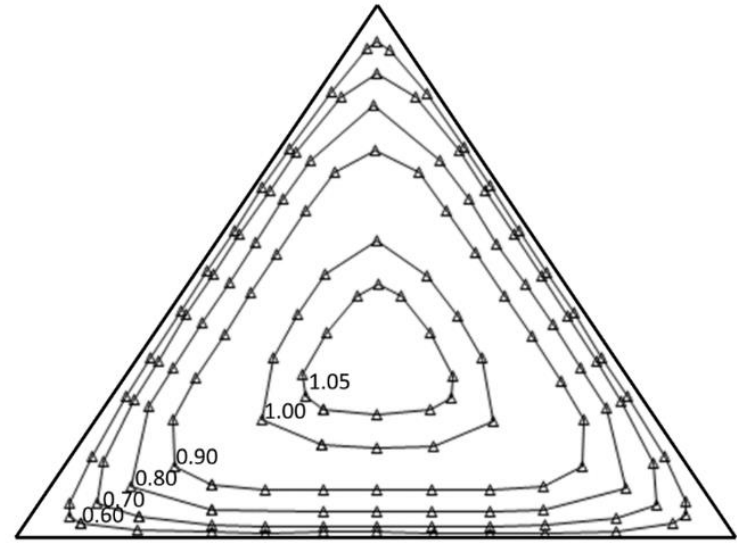

(b) Calculated

Figure 8. Comparison between measured and calculated velocity contours in triangular duct using Eq. (1). The measured velocity contours (a) are based on Nikuradse [9], while calculated velocity contours (b) are estimated by using the modified law-log law in the current study. 


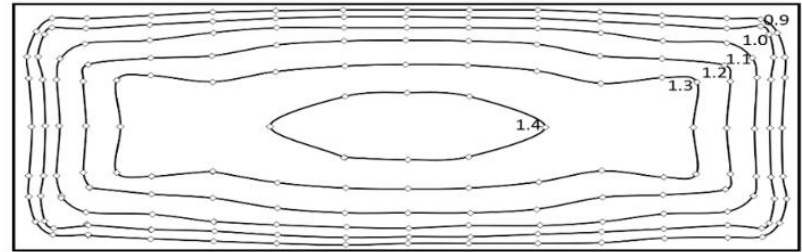

(a) Measured

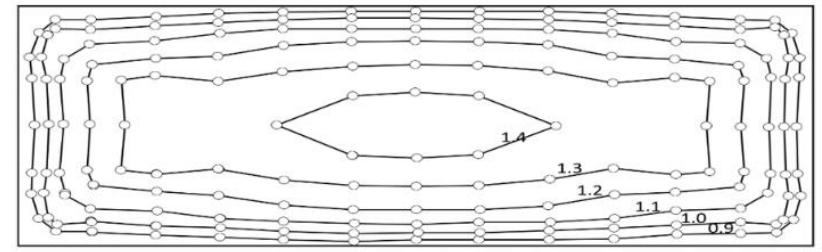

(b) Calculated

Figure 9. Comparison of measured isovelocity contours in rectangular duct. The measured velocity contours (a) are based on Nikuradse [9], while calculated velocity contours (b) are estimated by using the modified law-log law in the current study. 


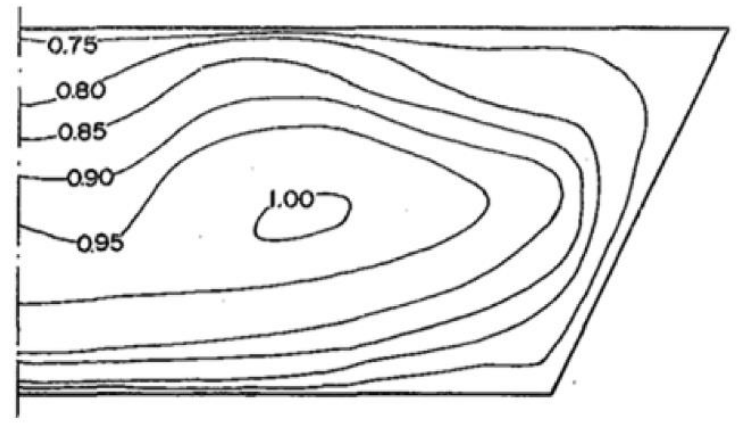

(a) Measured

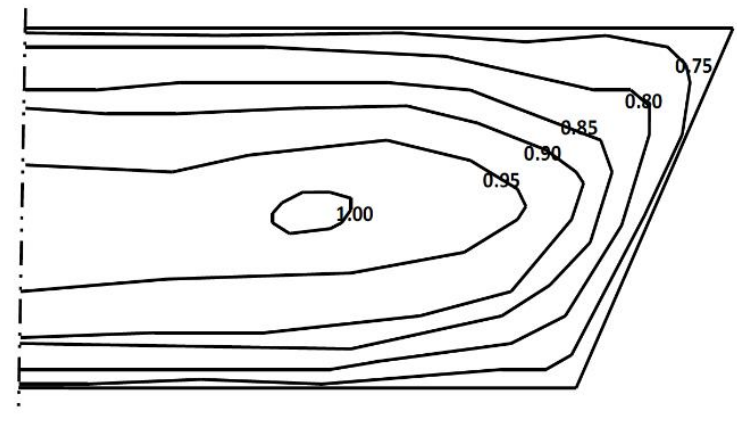

(b) Calculated

Figure 10. Comparison of measured isovelocity contours in a trapezoidal duct (corner angles were $60^{\circ}$ and $116^{\circ}$ ). The measured velocity contours (a) are based on Prinos et al. [29], while calculated velocity contours (b) are estimated by using the modified law-log law in the current study. 
Journal of Fluids Engineering

\section{List of Tables}

Table 1: Summary of hydraulic parameters used in experiments

\begin{tabular}{cccccc}
\hline Test No. & $\mathbf{h}(\mathbf{m m})$ & $\mathbf{b}(\mathbf{m m})$ & $\mathbf{b} / \mathbf{h}$ & $\mathbf{Q}(\mathbf{L} / \mathbf{s})$ & Reynolds No. \\
\hline \hline 1 & 87 & 300 & 3.45 & 14.0 & $1.27 \times 10^{5}$ \\
2 & 135 & 300 & 2.22 & 33.0 & $1.29 \times 10^{5}$ \\
\hline \hline
\end{tabular}


Journal of Fluids Engineering

Table 2: Averaged relative error of point velocity contours

\begin{tabular}{ll}
\hline \multicolumn{1}{c}{ Channel Type } & E \\
\hline \hline Trapezoidal duct [24] & $4.18 \%$ \\
Triangular duct [9] & $2.13 \%$ \\
Rectangular duct [9] & $3.47 \%$ \\
Rectangular channel (current study) & $5.09 \%$ \\
\hline \hline
\end{tabular}

